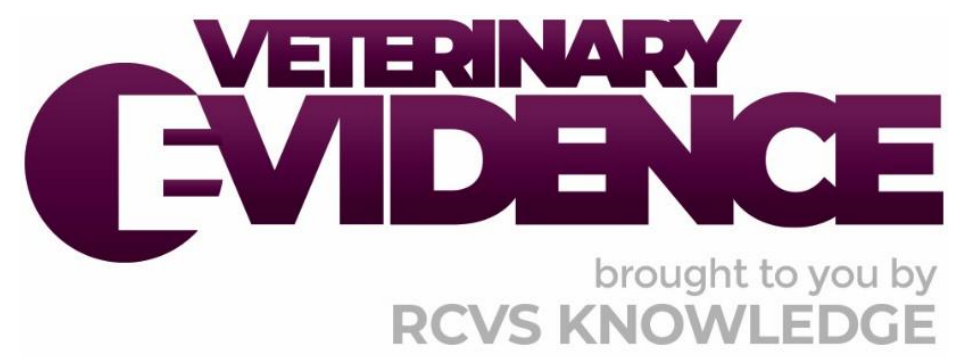

\title{
Are bisphosphonates a more effective treatment than intra-articular steroids in horses with distal hock osteoarthritis?
}

\author{
A Knowledge Summary by
}

Hannah Greene $M A^{1^{*}}$

\footnotetext{
${ }^{1}$ Washington State University College of Veterinary Medicine, Bustad Hall, Pullman, WA 99163

*Corresponding Author (hannah.greene@wsu.edu)
}

ISSN: 2396-9776

Published: 11 Mar 2020

in: Vol 5, Issue 1

DOI: 10.18849/VE.V5I1.235

Reviewed by: Janny de Grauw (DVM, PhD Dip., ECVAA) and Alastair Kay(BVSc, MS, DipACVS, MRCVS)

Next Review Date: 21 May 2020 


\section{KNOWLEDGE SUMMARY}

\section{Question}

In horses that are lame due to osteoarthritis of the distal tarsal joints (bone spavin), is intra-articular medication with corticosteroids compared to systemic bisphosphonate treatment more effective in longterm lameness reduction?

\section{Clinical bottom line}

\section{Category of research question}

\section{Treatment}

\section{The number and type of study designs reviewed}

Three papers were critically reviewed. Two were randomised controlled trials, and one was a retrospective study.

\section{Strength of evidence}

Weak

\section{Outcomes reported}

There is insufficient evidence to support the use of systemic bisphosphonates over intra-articular corticosteroids to treat distal hock osteoarthritis in horses.

\section{Conclusion}

Horses with distal hock osteoarthritis should not be treated with systemic bisphosphonates until further blinded randomised controlled trials are completed. Additionally, supportive evidence for the use of intraarticular corticosteroids as a treatment for degenerative hock osteoarthritis is limited to a retrospective study where modest, short-term improvements are reported: $58 \%$ of horses improved after an average of 56 days (Labens et al., 2007). Evidence does not support significant improvement in long-term outcomes: $50 \%$ of horses improved after 4 months (Watts et al., 2016) and only 38\% of horses improved after a mean follow-up period of 787 days (Labens et al., 2007).

\section{How to apply this evidence in practice}

The application of evidence into practice should take into account multiple factors, not limited to: individual clinical expertise, patient's circumstances and owners' values, country, location or clinic where you work, the individual case in front of you, the availability of therapies and resources.

Knowledge Summaries are a resource to help reinforce or inform decision making. They do not override the responsibility or judgement of the practitioner to do what is best for the animal in their care. 


\section{The evidence}

Labens et al. (2007) is a retrospective study that followed the outcomes of 51 horses treated with intraarticular (IA) corticosteroids for distal hock osteoarthritis (OA). The authors used lameness scores, radiographs and scintigraphy to assess the outcomes of treatment with IA corticosteroids in either the tarsometatarsal (TMT) or distal intertarsal (DIT) joints. The authors concluded that after a single treatment with an IA corticosteroid, lameness improved in 34/59 (58\%) of treated limbs at a median of 56 days post-treatment. At telephone follow-up a mean of 787 days after treatment, $38 \%$ of horses had a positive outcome: they were used as intended, had no detectable lameness according to the owner and were not receiving nonsteroidal anti-inflammatory drugs (NSAIDs). This study provides the strongest experimental design in absence of a randomised controlled trial among studies that examine IA corticosteroids as the sole treatment in chronic, degenerative OA. While the treatments were not uniform between cases, they do reflect the day-to-day clinical treatment of distal hock OA.

This study reports a positive correlation between treatment with IA corticosteroids for distal hock OA and a modest, improved outcome.

Gough et al. (2010) is a randomised controlled trial that compared two treatment groups of horses with distal hock OA. The first group was treated with a $1 \mathrm{mg} / \mathrm{kg}$ tiludronate IV infusion and the second group was given an IV placebo infusion. The study used lameness scores, level of exercise and radiographs to assess outcomes at day 60 . The authors concluded that the lameness scores for the tiludronate group were significantly lower than the placebo group at day $60(P=0.0318)$. Furthermore, they concluded that $60 \%$ of horses in the tiludronate group improved by 2 or more lameness scores at day 60. Despite the type of experimental design (randomised controlled trial), there were significant limitations to the quality of the evidence such that a wholescale change to clinical practice is not recommended based on this trial alone. These limitations are further addressed in the appraisal section below.

Watts et al. (2016) is a randomised controlled trial of resveratrol supplementation and IA triamcinolone to treat distal hock OA. Resveratrol is a compound with anti-inflammatory properties that is naturally found in grape skins. In this study the placebo group was treated with IA triamcinolone and a placebo powder (fermentation solubles, S. cerevisiae 1026, diatomaceous earth) 2 scoops fed every 12 hours. Additionally both groups were treated with $2 \mathrm{~g}$ phenylbutazone IV immediately after IA injection and $2 \mathrm{~g}$ phenylbutazone PO every 24 hours for the next 3-7 days. There was no control group (i.e. IA saline) to assess the efficacy of triamcinolone as a sole intervention, as the authors did not wish to withhold standard IA triamcinolone treatment from lame horses. To eliminate the majority of effects from IA triamcinolone, the authors chose to assess outcomes at 2 and 4 months post-treatment. At 2 months post-treatment, lameness was expected to recur in $90 \%$ of horses (Labens et al., 2007) and at 3 months post-treatment $50 \%$ of horses were expected to be lame (de Grauw et al., 2016). In effect, the authors assumed that treatment with IA triamcinolone alone will fail by either 2 or 4 months post-treatment and the outcome of resveratrol supplementation can be interpreted without IA triamcinolone treatment effects. The authors conclude that horses injected with IA triamcinolone and supplemented with resveratrol had better performance than horses injected with triamcinolone alone at 2 and 4 months post-treatment. While the efficacy of the resveratrol intervention is not the subject of this PICO question, Watts et al. (2016) found that 4 months after IA corticosteroid (triamcinolone) injection, only $35 \%$ of horses had returned to full work, confirming that long-term outcome of IA triamcinolone treatment is not favourable for distal tarsal OA. Further study limitations are outlined in the appraisal section below. 


\begin{tabular}{|c|c|}
\hline \multicolumn{2}{|l|}{ Labens et al. (2007) } \\
\hline Population: & $\begin{array}{l}\text { Horses treated at the University of Glasgow Veterinary School for OA } \\
\text { of the TMT and/or DIT joint between } 1998 \text { and } 2005 \\
\text { - Sex: } 35 \text { geldings, } 15 \text { mares, one stallion } \\
\text { - Age: Median = } 9 \text { years (range } 4-18 \text { years) } \\
\text { - Breed: } 28 \text { Thoroughbreds (TB), Warmbloods (WB) or TB x } \\
\text { WB crosses; } 23 \text { undisclosed breeds } \\
\text { - Use: } 29 \text { general purpose, } 10 \text { showjumping, four dressage, } \\
\text { two eventing, two hunting, four unknown use }\end{array}$ \\
\hline Sample size: & $n=51$ \\
\hline Intervention details: & 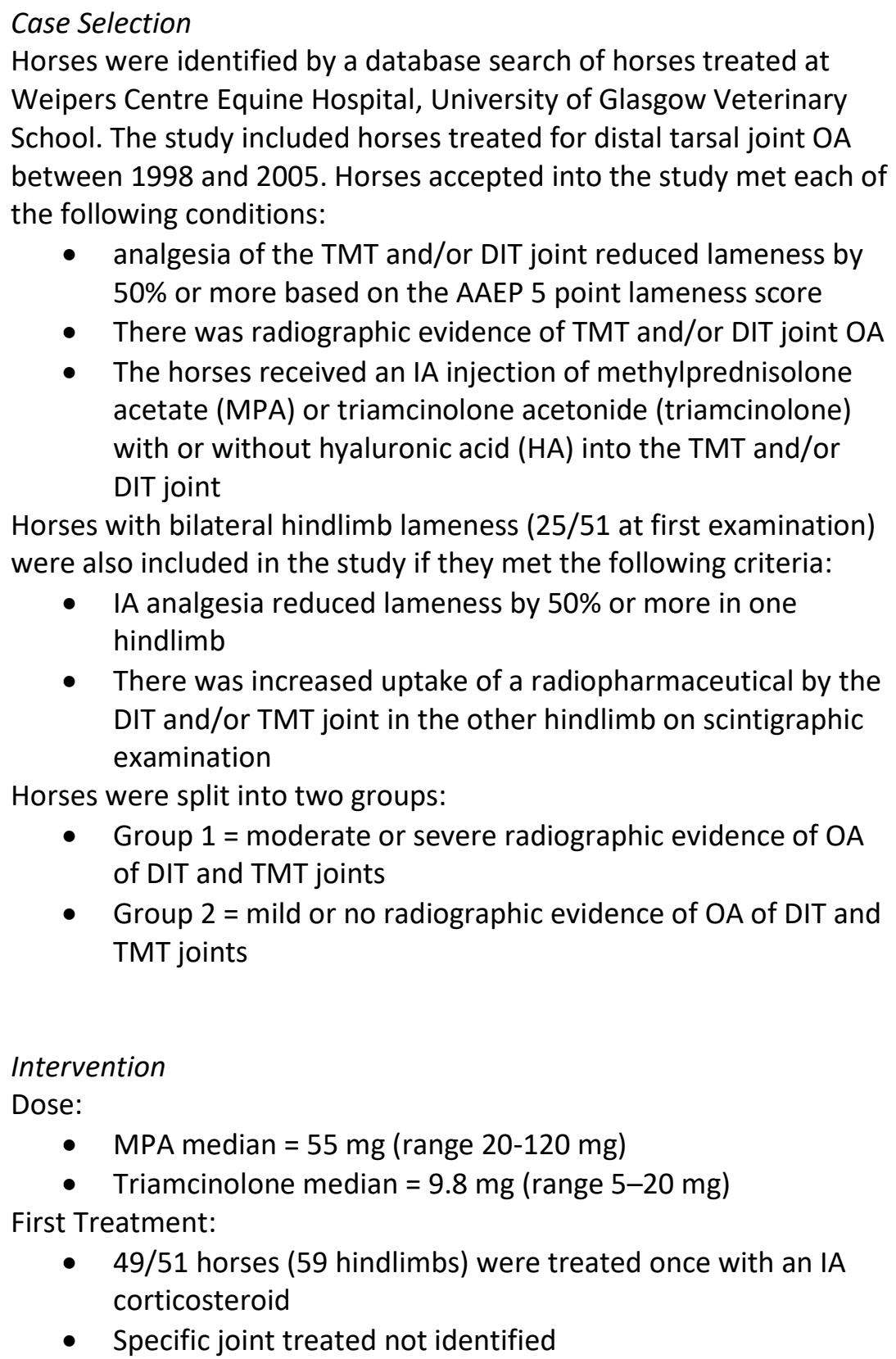 \\
\hline
\end{tabular}




\begin{tabular}{|c|c|}
\hline & $\begin{array}{l}\text { - Choice of IA corticosteroid was determined by the attending } \\
\text { clinician's preference: } \\
\circ \quad \text { Triamcinolone only in four hindlimbs } \\
\circ \quad \text { Triamcinolone with HA in } 17 \text { hindlimbs } \\
\circ \text { MPA only in } 38 \text { hindlimbs } \\
\text { - Median interval between first treatment and second exam = } \\
56 \text { days (range } 18-1436 \text { days) } \\
\text { - Median interval between the first and second treatment = } \\
69 \text { days } \\
\text { Second Treatment: } \\
\text { - } 14 / 51 \text { horses were treated two or more times with an IA } \\
\text { corticosteroid } \\
\text { - } 12 \text { of these horses (13 hindlimbs) were treated twice and re- } \\
\text { examined by the same clinician } \\
\circ \quad \text { MPA only in } 12 / 13 \text { hindlimbs } \\
\circ \quad \text { Triamcinolone with HA in } 1 / 13 \text { hindlimbs } \\
\text { - Joints treated: } \\
\circ \quad \text { DIT and TMT } 5 / 13 \text { hindlimbs } \\
\circ \quad \text { TMT only in } 8 / 13 \text { hindlimbs } \\
\text { - Median interval between second treatment and re- } \\
\text { examination = } 50 \text { days (range } 25-194 \text { days) }\end{array}$ \\
\hline Study design: & Retrospective study \\
\hline Outcome studied: & $\begin{array}{l}\text { Subjective Assessment: Lameness Scores } \\
\text { 1) Difference between lameness scores at initial and follow-up } \\
\text { examinations was calculated if the clinician was the same for } \\
\text { both exams } \\
\text { 2) The horse was classified as 'lame' or 'sound' if two different } \\
\text { clinicians performed initial and follow up examinations } \\
\text { - Positive outcome = horse fulfilled intended use without the } \\
\text { owner detecting lameness and without receiving oral NSAIDs } \\
\text { - Negative outcome (excluded from analysis) = horse } \\
\text { developed unrelated problems that prevented its return to } \\
\text { exercise and/or horse received surgical treatment } \\
\text { - Follow up information was obtained for } 42 / 51 \text { horses at a } \\
\text { mean of } 787 \text { days after the last appointment (range } 114- \\
\text { 1942 days) } \\
\text { Lameness variables assessed at initial and follow-up exam } \\
\text { Based on AAEP lameness score (0 = not lame, } 5 \text { = not weight } \\
\text { bearing; including half-point scores) } \\
\text { During initial exams lameness was assessed in the following } \\
\text { conditions: } \\
\quad \text { Walk and trot, straight line, hard surface } \\
\text { - Walk and trot, right and left circles on the lunge, } \\
\text { hard and soft surfaces } \\
\text { condition which exacerbated the lameness in the initial } \\
\text { exam. }\end{array}$ \\
\hline
\end{tabular}




\begin{tabular}{|c|c|}
\hline & $\begin{array}{l}\text { Objective Assessment: Radiographic Examination } \\
\text { - Radiographs were available at time of inclusion and were not } \\
\text { repeated after treatment } \\
\text { - Standing dorsoplantar, dorsolateral-plantaromedial oblique, } \\
\text { dorsomedial-plantarolateral oblique and lateromedial } \\
\text { radiographs of all affected tarsi } \\
\text { - Blinded assessment of radiographic signs of OA by first } \\
\text { author } \\
\text { O Signs included: irregular subchondral bone, } \\
\text { subchondral bone sclerosis, narrowed joint, } \\
\text { osteophytes, bony bridge formation, subchondral } \\
\text { bone lysis and ankylosis } \\
\text { Each sign was graded as absent, mild, moderate or } \\
\text { severe } \\
\text { Objective Assessment: Scintigraphy } \\
\text { 12/51 horses underwent scintigraphy (lateral and plantar } \\
\text { views) } \\
\text { - Only included horses with bilateral lameness } \\
\text { Six veterinary surgeons experienced in scintigraphic } \\
\text { interpretation conducted a blind assessment of the images }\end{array}$ \\
\hline $\begin{array}{l}\text { Main findings: } \\
\text { (relevant to PICO question): }\end{array}$ & 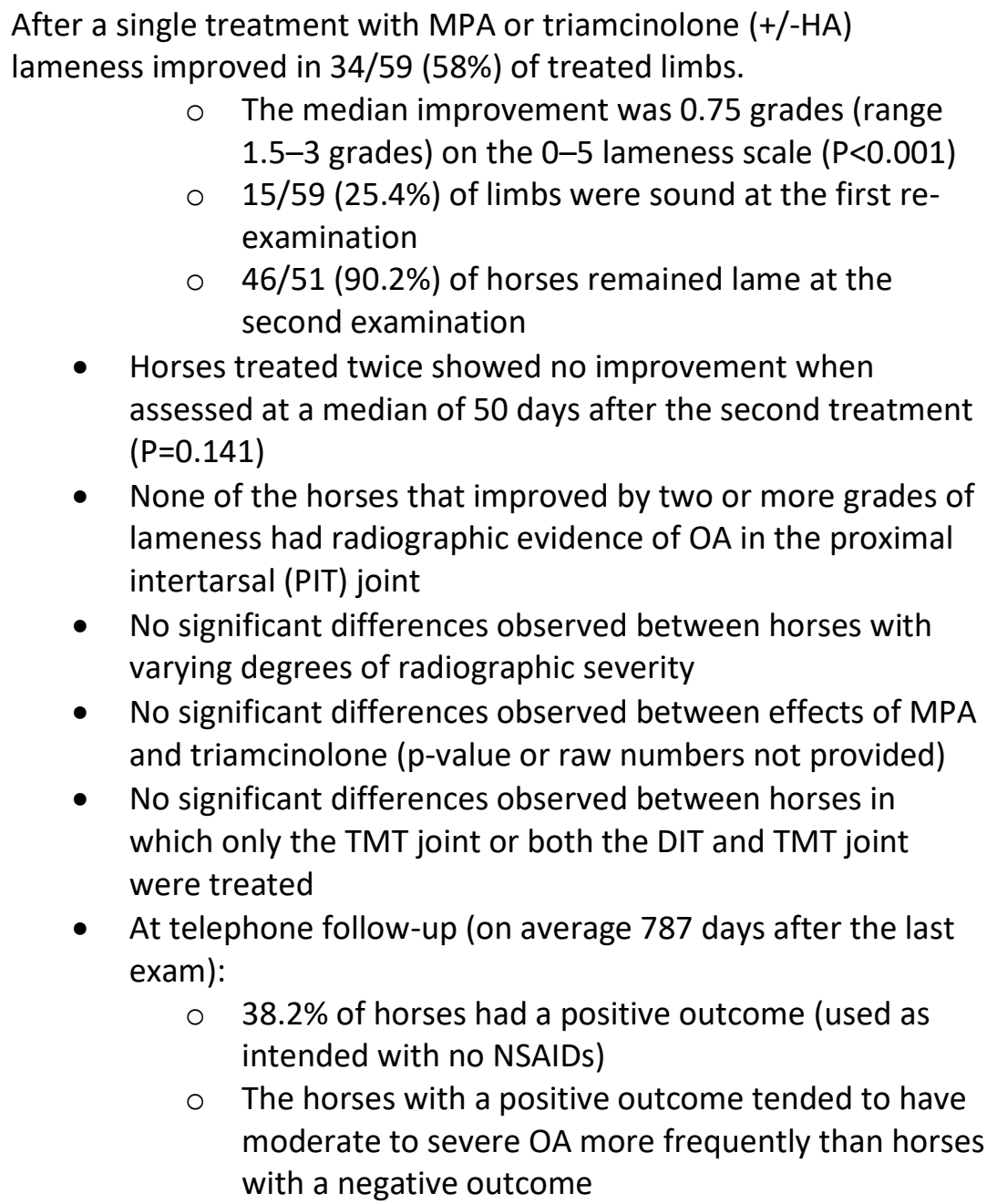 \\
\hline
\end{tabular}




\begin{tabular}{|c|c|}
\hline & $\begin{array}{l}\text { - } 12 / 12 \text { horses showed significant radiopharmaceutical } \\
\text { uptake in the distal tarsal joints } \\
\circ \text { Scintigraphy was available at time of inclusion and } \\
\text { not repeated after treatment } \\
\circ \quad \text { The horses with diffuse uptake showed significant } \\
\text { improvement in their lameness score after one } \\
\text { treatment ( } \mathrm{P}=0.032) \text {. } \\
\circ \quad \text { The horses with focal uptake did not show } \\
\text { significant improvement } \\
\circ \quad \text { There was no significant association between the } \\
\text { type of uptake (i.e. focal or diffuse) and the } \\
\text { outcome of treatment at telephone follow-up }\end{array}$ \\
\hline Limitations: & $\begin{array}{l}\text { - As a retrospective study, this study lacks a control group and } \\
\text { cannot prove causation; i.e., differences between } \\
\text { treatments cannot be causally linked to treatment alone, as } \\
\text { disease status may have influenced treatment allocation to } \\
\text { MPA or triamcinolone. Further limitations include: } \\
\text { - Lameness grading was subjective and not blinded } \\
\text { - The horses were from a wide age range (4-18 years) and } \\
\text { effect between age and outcome was not calculated } \\
\text { - The intervention (MPA or triamcinolone +/-HA, and dose) } \\
\text { was not uniform between groups } \\
\text { - No information on ancillary treatment/chondroprotective } \\
\text { supplements etc. } \\
\text { Follow-up exams and treatments did not occur within a } \\
\text { uniform date range and were not performed by the same } \\
\text { observer } \\
\text { The inclusion criteria for distal hock OA (positive response to } \\
\text { IA analgesia) did not rule out other conditions such as PSD } \\
\text { and intertarsal ligament enthesopathy. These other } \\
\text { differentials respond differently to treatment and } \\
\text { scintigraphic examination } \\
\text { - Insufficient power for radiographic and scintigraphic } \\
\text { evidence. Imaging was not conducted following treatment }\end{array}$ \\
\hline
\end{tabular}

Gough et al. (2010)

\begin{tabular}{|c|c|}
\hline Population: & $\begin{array}{l}\text { Horses in the UK and Ireland with a clinical diagnosis of distal hock } \\
\text { OA } \\
\text { - Sex: } 35 \text { non-pregnant mares, } 73 \text { geldings (108 initially } \\
\text { included) } \\
\text { - Age: mean } 11 \text { years (range } 5-20 \text { years) } \\
\text { - Use: pleasure horses, event horses, showjumpers or other }\end{array}$ \\
\hline Sample size: & $\mathrm{n}=108$ initially included; only 87 met the final inclusion criteria \\
\hline Intervention details: & $\begin{array}{l}\text { Case Selection } \\
\text { Horses with a clinical diagnosis of distal hock OA that met each of } \\
\text { the following conditions: } \\
\text { - Clinical signs of spontaneous lameness from } 6 \text { weeks-1 year } \\
\text { in duration }\end{array}$ \\
\hline
\end{tabular}




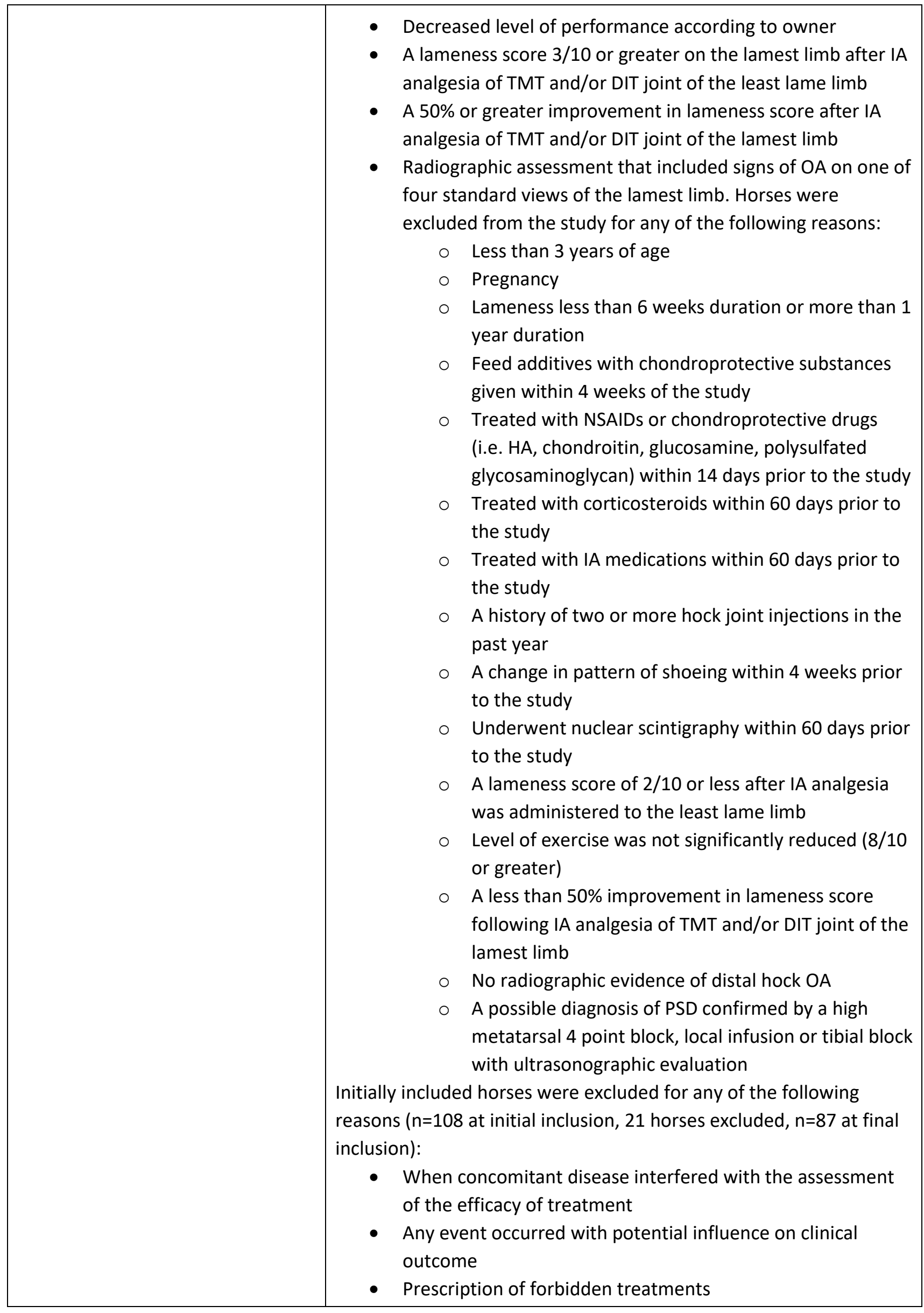


- Horses were diagnosed with another orthopedic problem on day 60 that was not apparent on day 0

Horses were split into two groups $(n=87)$ :

- Group 1 = Tiludronate group, 42 horses

- Group 2 = Placebo group, 45 horses

- Imbalanced groups not addressed

- 40 horses needed in each group for $80 \%$ power to evidence an average of one lameness grade difference

Intervention

Dose:

- Group $1=1 \mathrm{mg} / \mathrm{kg}$ tiludronate diluted with normal saline to 1 litre by IV infusion over 30 minutes

- Group $2=1 \mathrm{mg} / \mathrm{kg}$ placebo powder diluted with normal saline to 1 litre by IV infusion over 30 minutes

First Treatment, Day 0:

- Treatments were determined by a biometrician-generated randomisation list

- Horses were divided into blocks with four horses in each block. ("In each list, treatments were randomly allocated by blocks of four horses (two tiludronate treated and two placebo horses per block)." Whether or not there was a group of three is unspecified.)

- Double blinded: Neither the owner nor the veterinarian knew if the infusion was the treatment or the placebo at day 0

- All horses were given IV sedation before infusion $(20 \mathrm{mcg} / \mathrm{kg}$ bwt detomidine hydrochloride or $40 \mathrm{mcg} / \mathrm{kg}$ bwt romifidine)

Second Treatment, Day 60:

- Horses with an inadequate response at day 60 were given 1 $\mathrm{mg} / \mathrm{kg}$ bwt tiludronate diluted with normal saline by IV infusion over 30 minutes

- Day 60 treatments were not blinded so there was no placebo administered

During the trial horses could receive the following treatments:

- Hoof trimming or reshoeing. The type of shoe could not be altered

- NSAIDs. Horses with lameness were treated with NSAIDs if deemed necessary (e.g. Phenylbutazone or flunixin). Horses with a concomitant disease such as colic or trauma were also treated with NSAIDs (e.g. phenylbutazone, flunixin meglumine), butylscopolamine or metamizole but not antimicrobials In each case there had to be 15 days between treatment and the next control visit

- Feed additives. Horses who had been receiving chondroprotective feed additives in the four weeks prior to the study continued to receive these additives at the same 


\begin{tabular}{|c|c|}
\hline & $\begin{array}{l}\text { dose throughout the studyNo other treatments were } \\
\text { allowed }\end{array}$ \\
\hline Study design: & Randomised controlled trial \\
\hline Outcome studied: & $\begin{array}{l}\text { Subjective Assessment: Lameness Scores } \\
\text { - Lameness was assessed on a } 10 \text { point scale based on } \\
\text { clinician observation. Not specified if same or different } \\
\text { clinician } \\
\text { - Lameness was assessed on a straight line on hard ground } \\
\text { - Lameness was monitored at days } 0,60 \text { and } 120 \\
\text { On days } 60 \text { and } 120 \text { critical lameness scores were } \\
\text { obtained: lameness was assessed on the most lame } \\
\text { limb after the least lame hock was given IA } \\
\text { analgesia } \\
\text { - Exercise was graded on a } 10 \text { point scale } \\
\text { - Exercise grading scores were specific to the horse's } \\
\text { discipline (e.g. racing, trotters, showjumpers and eventers, } \\
\text { dressage, pleasure and endurance) } \\
\text { Objective Assessment: Radiographs } \\
\text { - Radiographic findings were compared between the } \\
\text { treatment and control group. } \\
\text { Radiographic findings were not graded by severity of disease } \\
\text { Findings noted included: thickening of subchondral bone, } \\
\text { subchondral bone lysis, subchondral bone sclerosis, } \\
\text { narrowing or loss of joint space, periarticular osteophytes, } \\
\text { periosteal new bone }\end{array}$ \\
\hline $\begin{array}{l}\text { Main findings: } \\
\text { (relevant to PICO question): }\end{array}$ & 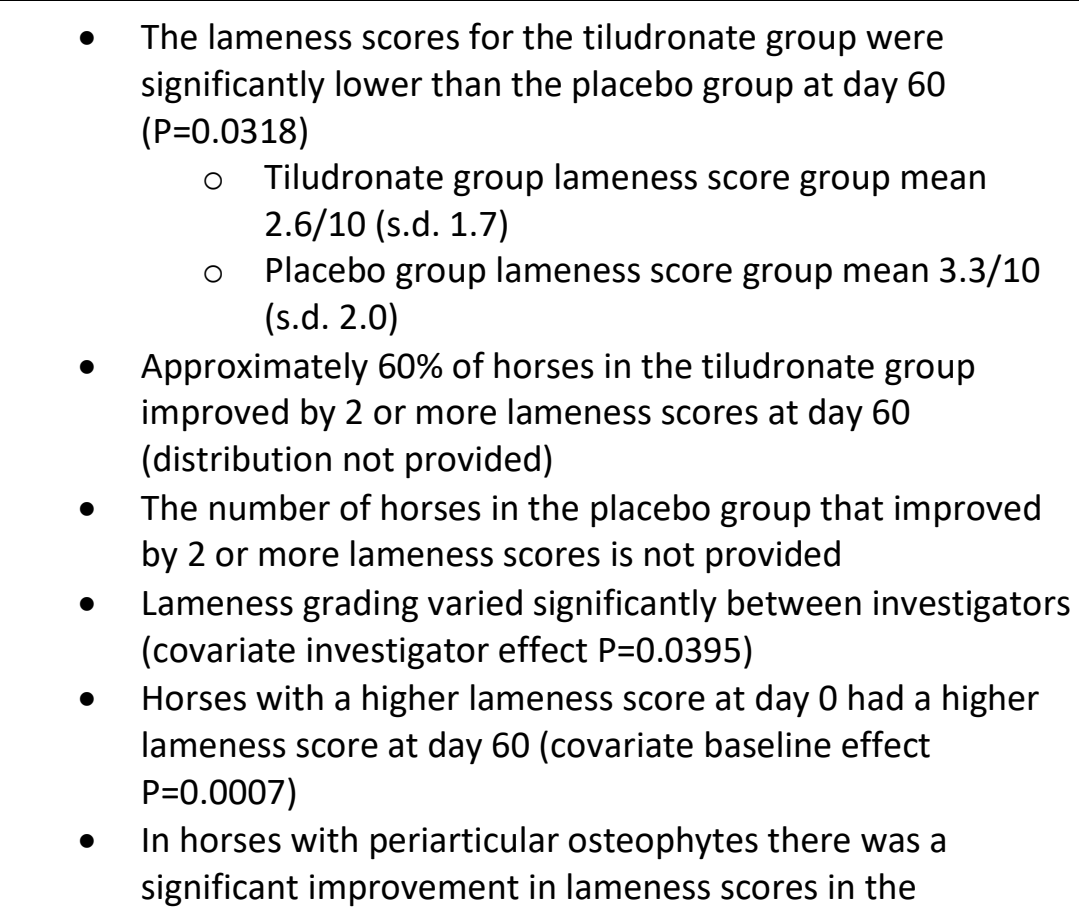 \\
\hline
\end{tabular}




\begin{tabular}{|c|c|}
\hline & $\begin{array}{l}\text { tiludronate group as compared to the placebo group } \\
(P=0.006) \text {. Number of horses with periarticular osteophytes } \\
\text { or subchondral bone thickening not given }\end{array}$ \\
\hline Limitations: & $\begin{array}{l}\text { - The } 60 \text { day outcome of the placebo group is not provided } \\
\text { - } \quad \text { Trom day } 60 \text {, the study was no longer blinded } \\
\text { part of the regulatory licensing trial. Two authors work for } \\
\text { CEVA and the third author was paid by CEVA for his clinical } \\
\text { expertise. Because the study was not double blinded past } \\
\text { day } 60 \text {, this could introduce bias } \\
\text { - The study relies on the investigator's clinical experience to } \\
\text { eliminate horses with PSD. It was also assumed that the } \\
\text { majority of horses with PSD would not have a greater than } \\
\text { 50\% positive response to TMT IA analgesia within } 10 \\
\text { minutes (Dyson and Romero, } 1993 \text { and Dyson, } 1994 \text { ) } \\
\text { Outcomes were assessed with subjective lameness grading } \\
\text { that varied significantly between investigators } \\
\text { There was a significant interaction between investigator } \\
\text { (P=0.0083) and treatment (P=0.0223) in the exercise results. } \\
\text { The authors suggest this was due to differences in at home } \\
\text { exercise protocols between investigators, but other biases } \\
\text { could be responsible. As a result, improvement in exercise } \\
\text { scores could not be associated with treatment } \\
\text { The statistical results on lameness did not include a p-value } \\
\text { for a possible interaction between treatment and } \\
\text { investigator. Including this p-value would provide more } \\
\text { evidence that the treatment effect on lameness was not due } \\
\text { to differences in investigator } \\
\text { - There was a significant difference in bodyweight between } \\
\text { the two groups. The placebo group had a mean weight of } \\
568 \text { kg, while the tiludronate group had a mean weight of } \\
521 \text { kg (P=0.01). Differences in bodyweight are difficult to } \\
\text { interpret without breed information and likely clinically } \\
\text { irrelevant } \\
\text { Results were only presented in percentages, means, } \\
\text { standard deviations and p-values. Frequencies (e.g. } 5 / 9 \\
\text { horses) were not supplied } \\
\text { ine radiographic evidence exclusion criteria was based on } \\
\text { standardised, objective grading scale of radiographic lesions } \\
\text { we The authors do not specify that adverse events } \\
\text { - }\end{array}$ \\
\hline
\end{tabular}




\begin{tabular}{|c|c|}
\hline \multicolumn{2}{|l|}{ Watts et al. (2016) } \\
\hline Population: & $\begin{array}{l}\text { Horses in the Southern US with hindlimb lameness or poor } \\
\text { performance } \\
\text { - Sex: } 12 \text { non-pregnant mares, } 28 \text { geldings, one stallion } \\
\text { - Breed: } 10 \text { warmbloods, } 21 \text { Quarter Horses or Paints, nine } \\
\text { Thoroughbreds, one Arabian } \\
\text { - Mean Age: } 12.4 \text { (+/- } 6.5) \text { in treatment group; } 10.7+/-6.0 \text { in } \\
\text { placebo group } \\
\text { - Use: dressage (8), eventing (7), jumping (5), western } \\
\text { performance (11), pleasure or trail riding (3) and western } \\
\text { show (7). Use not-specified for four horses lost to follow up. }\end{array}$ \\
\hline Sample size: & $n=45$ \\
\hline Intervention details: & 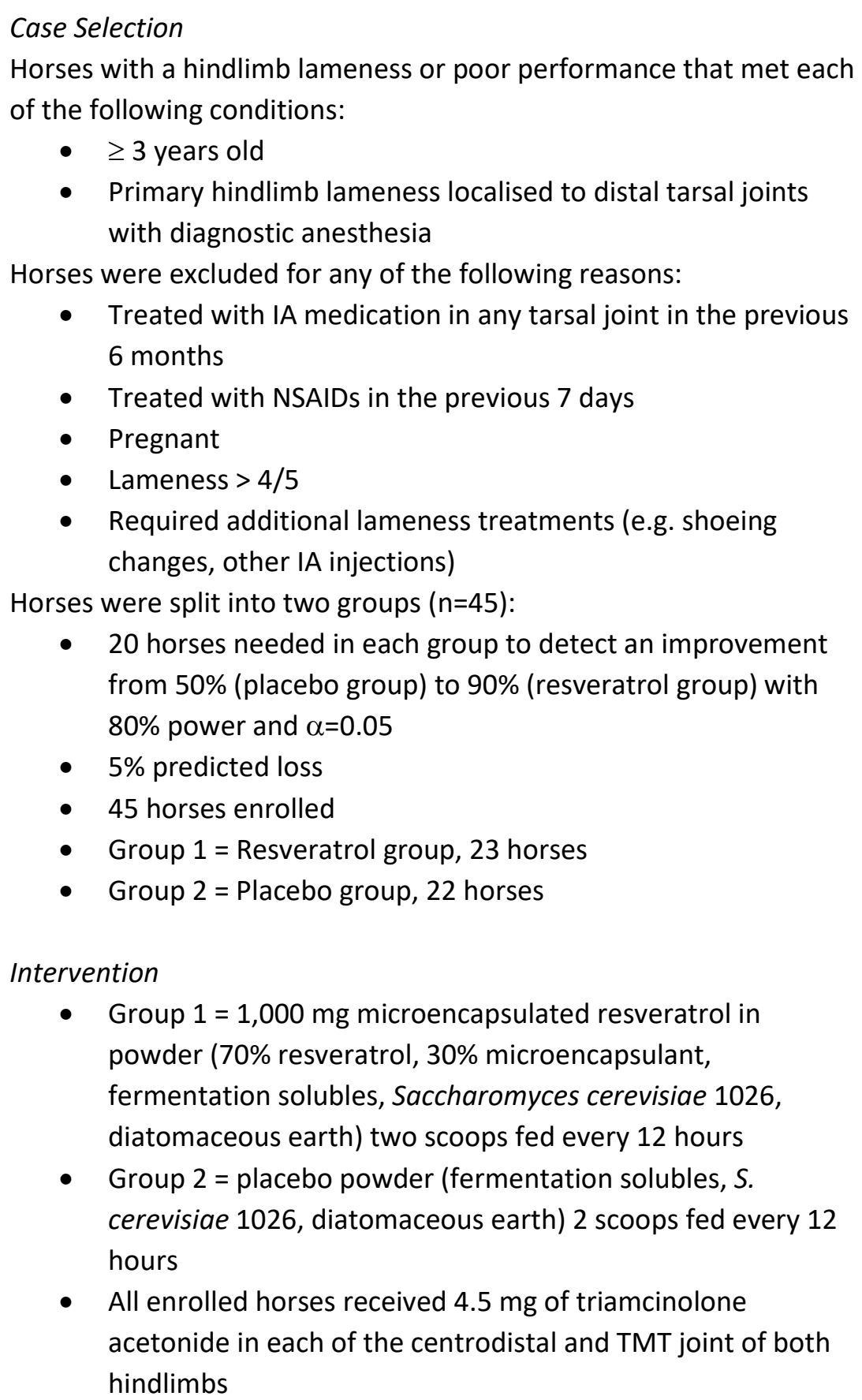 \\
\hline
\end{tabular}




\begin{tabular}{|c|c|}
\hline & $\begin{array}{l}\text { - Four horses also received } 62.5 \mathrm{mg} \text { of amikacin in each joint } \\
\text { (this was a single clinician's preference, it was not specified } \\
\text { in which group these horses were enrolled) } \\
\text { - IA injection confirmed by either } 1 \text { ) joint fluid in needle hub } \\
\text { or 2) radiography or fluoroscopy to confirm needle } \\
\text { placement } \\
\text { - All horses were treated with } 2 \mathrm{~g} \text { phenylbutazone IV after IA } \\
\text { injections } \\
\text { Owners instructed to give } 2 \mathrm{~g} \text { phenylbutazone PO q } 24 \mathrm{~h} \text { for } \\
3-7 \text { days and return to full work in 3-7 days depending on } \\
\text { clinician instructions. Diet, turnout and exercise programs } \\
\text { maintained as before study enrollment } \\
\text { Owners recorded medications or supplements added or } \\
\text { stopped during treatment period }\end{array}$ \\
\hline Study design: & Randomised controlled trial \\
\hline Outcome studied: & $\begin{array}{l}\text { Subjective Assessment: Lameness Scores } \\
\text { - Lameness was assessed on a } 5 \text { point scale based on clinician } \\
\text { observation. Lameness was also noted to be unilateral or } \\
\text { bilateral } \\
\text { - Lameness was assessed on a } 40 \text { m straight line and in a } 20 \text { m } \\
\text { half circle on hard ground in both directions } \\
\text { - Lameness was monitored at enrollment and } 4 \text { months post- } \\
\text { enrollment } \\
\text { - Diagnostic anesthesia was only performed at enrollment } \\
\text { Subjective Assessment: Level of Exercise } \\
\text { - Owner questionnaire at } 2 \text { and } 4 \text { months } \\
\text { - Clinician asked owner or rider about horse's perceived } \\
\text { performance } \\
\text { Objective Assessment: Inertial Sensor System } \\
\text { - Parameters measured were pelvic asymmetry (MAXDIFF and } \\
\text { MINDIFF) and vertical pelvic movement vs. expected pelvic } \\
\text { movement (A1:A2 ratio) }\end{array}$ \\
\hline $\begin{array}{l}\text { Main findings: } \\
\text { (relevant to PICO question): }\end{array}$ & $\begin{array}{l}\text { - Two horses in each group (four total) lost to follow-up at } 2 \\
\text { months; } 41 \text { horses analysed } \\
2 \text { months after enrollment, the percentage of horses whose } \\
\text { performance was better, compared with worse or the same, } \\
\text { was significantly }(P=0.04) \text { higher for the resveratrol group } \\
(20 / 21[95 \%]) \text { than for the placebo group }(14 / 20[70 \%]) \\
4 \text { months after enrollment, the percentage of horses whose } \\
\text { performance was better, compared with worse or the same, } \\
\text { was still significantly }(\mathrm{P}=0.02) \text { higher for the resveratrol } \\
\text { group }(18 / 21[86 \%]) \text { than for the placebo group }(10 / 20\end{array}$ \\
\hline
\end{tabular}




\begin{tabular}{|c|c|}
\hline & $\begin{array}{l}\text { [50\%]). } 2 \text { months after enrollment } 70 \%(14 / 20) \text { of riders } \\
\text { reported that the horse's performance was better in the IA } \\
\text { triamcinolone only group compared to baseline } \\
\text { - } 4 \text { months after enrollment } 50 \%(10 / 20) \text { of horses improved } \\
\text { in the IA triamcinolone only group compared to baseline } \\
\text { - } 4 \text { months after treatment, } 35 \% \text { of horses had returned to } \\
\text { full work in placebo group } 2 \text { (vs 38\% of horses in treatment } \\
\text { group 1; not significant) }\end{array}$ \\
\hline Limitations: & $\begin{array}{l}\text { - Many key performance indicators in the rider questionnaire } \\
\text { were not significantly different between groups. These } \\
\text { included: whether the horse had returned to full work (yes } \\
\text { vs no), whether signs of lameness were present (yes vs no), } \\
\text { performance compared with expectations (at/above vs } \\
\text { below) and whether the owner/rider was satisfied with how } \\
\text { the horse was doing (yes vs no) } \\
\text { - There was no difference in pelvic asymmetry from inertia } \\
\text { - Consor between the two groups } \\
\text { - changes in A1:A2 ratio (only scatterplots and p-values given) } \\
\text { - Other differentials for distal tarsal lameness (e.g. proximal } \\
\text { suspensory desmopathy) were not excluded } \\
\text { Radiographic evidence was not considered }\end{array}$ \\
\hline
\end{tabular}

\section{Appraisal, application and reflection}

Labens et al. (2007) provides the strongest experimental design in support of IA corticosteroids as the sole treatment in chronic, degenerative OA. There is no randomised controlled trial to support the use of IA corticosteroids as a treatment for degenerative hock OA. This study reports a positive correlation between treatment with IA corticosteroids for distal hock OA and a modest, improved outcome.

The limitations of the study include non-uniform treatments (doses, site of injection and choice of corticosteroid varied), non-uniform time to follow-up, and non-uniform time between subsequent exams and treatments. Another weakness was that the cases studied did not conclusively rule out other disease processes that would not respond to IA corticosteroid treatment (e.g. proximal suspensory desmitis and intertarsal ligament enthesopathy). One strength of this study is that it uses a moderately large sample size $(n=51)$. More importantly, it provides the strongest experimental design in absence of a randomised controlled trial among studies that examine IA corticosteroids as the sole treatment in chronic, degenerative OA. While the treatments were not uniform between cases, they do reflect the day-to-day clinical treatment of distal hock OA. The modest therapeutic success in this study indicates that clinicians can expect about half of horses to have a positive outcome 2 months after treatment, but only 34/59 (58\%) of horses to have a long-term positive outcome. These outcomes are restricted to IA corticosteroid treatment as a sole intervention and do not consider other treatments for distal hock OA.

Gough et al. (2010) is a randomised controlled trial that evaluated efficacy of tiludronate as a treatment for distal hock OA. The authors concluded that the lameness scores for the tiludronate group were significantly lower than the placebo group at day $60(\mathrm{P}=0.0318)$. Furthermore, they concluded that $60 \%$ of horses in the tiludronate group improved by 2 or more lameness scores at day 60. Finally, the authors report that for the subset of horses with periarticular osteophytes in both groups, lameness scores were lower in the tiludronate group as compared to the placebo group $(P=0.006)$. 
There are a number of limitations associated with this study, the main ones are highlighted here. First, the distribution of lameness scores for both the placebo group and the treatment group was not reported. Second, the study became unblinded at/after day 60 . The study was also funded by the makers of Tildren ${ }^{\circledR}$ (tiludronate disodium). While this funding source was clearly disclosed, it may have introduced bias. Third, lameness grading varied significantly between investigators (covariate investigator effect $P=0.0395$ ), which may have impacted outcome assessment. There was also a significant effect of investigator $(\mathrm{P}=0.0083)$ and an interaction between investigator and treatment $(P=0.0223)$ in the exercise results. This suggests that differences in at home exercise protocols were significant between investigators and centres. As a result, improvement in exercise scores could not be utilised as a treatment outcome as this was more likely to be associated with investigator rather than treatment. A final limitation is that this study does not address potential side effects of tiludronate. Despite the type of experimental design (randomised controlled trial), there were significant limitations to the quality of the evidence such that a wholescale change to clinical practice is not recommended based on this trial alone.

Watts et al. (2016) is a randomised controlled trial of resveratrol supplementation and IA triamcinolone to treat distal hock OA. The authors conclude that horses injected with IA triamcinolone and supplemented with resveratrol had better performance than horses injected with triamcinolone alone at 2 and 4 months posttreatment. Better performance was indicated subjectively by owner reported performance improvement and objectively by vertical pelvic movement measured by inertial sensor system (The A1:A2 ratio is calculated for each hindlimb and compares the horse's actual vertical pelvic movement with an expected vertical pelvic movement). Yet certain key performance indicators did not vary between the treatment and placebo groups: subjective lameness scores by a clinician, pelvic asymmetry from inertial sensor, and the owner/rider's perception that the horse had returned to full work. While the efficacy of the resveratrol intervention is not the subject of this PICO question, Watts et al. (2016) found that 4 months after IA corticosteroid (triamcinolone) injection, only $35 \%$ of horses had returned to full work, confirming that long-term outcome of IA triamcinolone treatment is not favourable for distal tarsal OA.

Evaluating the comparative efficacy of treatments for distal hock OA comes with many challenges. One challenge is that to date, there is no published randomised controlled trial to directly compare the efficacy of IA corticosteroids with systemic bisphosphonates. The strongest evidence for either treatment comes from randomised controlled trials where each intervention is examined separately. Watts et al. (2016) is a randomised controlled trial of resveratrol supplementation and IA triamcinolone to treat distal hock OA. While the efficacy of the resveratrol intervention is not the subject of this PICO question, Watts et al. (2016) does provide evidence that long-term outcome of IA triamcinolone treatment for distal tarsal OA is suboptimal: at 2 months post IA triamcinolone treatment, 70\% (14/20) horses' performance improved while at 4 months post IA triamcinolone treatment, only 50\% (10/20) of horses' performance improved.

De Grauw et al. (2016) conducted another randomised controlled trial that compared efficacy of IA triamcinolone with IA triamcinolone + hyaluronate acid (HA). It was excluded from this knowledge summary because OA was not confirmed radiographically and no tarsal joints were included in the study; therefore, conclusions about the intervention relative to tarsal OA cannot be drawn. But this study does shed light on IA triamcinolone efficacy at various intervals post-treatment. At 3 weeks post-treatment, $88 \%$ of patients treated with IA triamcinolone had improved by 2 lameness grades. At 3 months post-treatment, owners reported only $50 \%$ of horses were back in full work, which is very similar to the proportion found by Watts et al. (2016). Again, there was no placebo control group due to ethical implications of withholding treatments from lame horses. De Grauw et al. (2016) also note that the 3 week improvement in lameness may in part have been due to the resting protocol they implemented.

Another prospective case series, although investigating the outcomes of a different treatment (IA ethanol injection) in cases of distal tarsal joint OA (Lamas et al., 2012), is also relevant to the PICO question at hand, given the study's population and inclusion criteria: of the 24 horses included, all horses had lameness recur 
within 4 months of receiving IA corticosteroids (triamcinolone or MPA) in the TMT joint (Lamas et al., 2012). This suggests that failure of IA corticosteroids for long-term management of distal tarsal OA is certainly not uncommon.

While IA corticosteroids are commonly used in everyday practice, prospective, randomised controlled trials with adequate power are necessary to assess their efficacy in treating distal hock OA. While it may not be ethically feasible to include a control group treated with IA saline in these studies, a non-treated group with controlled exercise should be included at a minimum. Additionally, placement of IA treatments should be confirmed radiographically as injection into distal tarsal joints - especially the DIT joint - is not always accurate (Seabaugh et al., 2017 and Hoaglund et al., 2019). Additional blinded randomised controlled trials are needed to assess efficacy of bisphosphonate treatment for distal hock OA, as various shortcomings for Gough et al. (2010) were noted above. Regardless of the intervention studied, a combination of subjective and objective outcomes should be assessed. These may include (blinded) lameness scores, rider reported performance improvement, and ideally some form of quantitative motion analysis (e.g. vertical pelvic movement from inertial motion unit sensor systems).

\section{Methodology Section}

\begin{tabular}{|c|c|}
\hline $\begin{array}{r}\text { Databases searched and dates } \\
\text { covered: }\end{array}$ & $\begin{array}{l}\text { CAB Abstracts on the OVID Platform } 1973 \text { to } 2018 \text { Week } 19 \\
\text { PubMed accessed via the NCBI website } 1910 \text { to May } 2018\end{array}$ \\
\hline Search terms: & $\begin{array}{l}\text { CAB Abstracts } \\
\text { (equine* or horse* or equus or equid* or mare or mares or } \\
\text { broodmare* or 'brood mare*' or pony or ponies or filly or fillies or } \\
\text { colt or colts or yearling* or stallion* or thoroughbred* or } \\
\text { standardbred* or racehorse* or 'race horse*').mp. or (exp horses/ } \\
\text { or exp equus/ or exp equidae/ or exp mares/ or exp colts/ or exp } \\
\text { foals/ or exp stallions/ or exp thoroughbred/ or exp racehorses/) } \\
\text { AND } \\
\text { (arthropat* or arthrit* or osteoarthrit* or osteo-arthrit* or synovitis } \\
\text { or tenosynovitis or 'joint disease*' or OA or DJD or osteoarthrosis or } \\
\text { lame or lameness or spavin or gait).mp. or (exp osteoarthritis/ or } \\
\text { exp arthritis/ or exp joint diseases/) } \\
\text { AND } \\
\text { (tarsal* or tarsus* or carpus* or carpal*).mp. or exp tarsus/ or exp } \\
\text { carpus/ } \\
\text { AND } \\
\text { ((corticosteroid* or glucocorticoid* or corticoid* or dexamethason* } \\
\text { or methylprednisolon* or triamcinolon* or TMC or betamethason* } \\
\text { or prednisolon* or prednison* or prednicare* or steroid*).mp. or } \\
\text { (exp prednisolone/ or exp prednisone/ or exp glucocorticoids/ or } \\
\text { exp steroids/) } \\
\text { OR } \\
\text { (bisphosphonat* or biphosphonat* or bisphosponat* or } \\
\text { biphosponat* or disphosponat* or diphosphonat* or diphosponat* } \\
\text { or disphosphonat* or tiludron* or clodron*)) } \\
\text { PubMed } \\
\text { (horse OR equine OR equus OR equidae OR equid OR mare OR } \\
\text { broodmare OR "brood mare" OR pony OR filly OR colt OR yearling }\end{array}$ \\
\hline
\end{tabular}




\begin{tabular}{|c|c|}
\hline & $\begin{array}{l}\text { OR stallion OR thoroughbred OR standardbred OR racehorse OR } \\
\text { "race horse") } \\
\text { AND } \\
\text { (arthropathy OR arthritis OR osteoarthritis OR osteo-arthritis OR } \\
\text { synovitis OR tenosynovitis OR “joint disease" OR OA OR DJD OR } \\
\text { Osteoarthrosis OR lame OR lameness OR spavin OR gait) } \\
\text { AND } \\
\text { (tarsal OR tarsus OR carpal OR carpus) } \\
\text { AND } \\
\text { ((corticosteroid OR glucocorticoid OR corticoid OR dexamethasone } \\
\text { OR methylprednisolone OR triamcinolone OR TMC OR } \\
\text { betamethasone OR prednisolone OR prednisone OR prednicare OR } \\
\text { steroid) } \\
\text { OR } \\
\text { (bisphosphonate OR biphosphonate OR bisphosphonate OR } \\
\text { biphosponate OR disphosponate OR diphosphonate OR } \\
\text { diphosponate OR disphosphonate OR tiludronate OR tiludronic OR } \\
\text { clodronate OR clodronic)) }\end{array}$ \\
\hline Dates searches performed: & 21 May 2018 \\
\hline
\end{tabular}

\section{Exclusion / Inclusion Criteria}

Exclusion: Papers that did not answer the PICO question were excluded for the following reasons:

1. the therapeutic intervention was not a corticosteroid or a bisphosphonate (e.g. gold, resveratrol, NSAIDs, surgery, ethanol, polysulfated glycosaminoglycans, hyaluronic acid, dimethyl sulphoxide), or

2. the therapeutic interventions were not administered according to the PICO requirements (i.e. corticosteroids were not given intra-articularly or bisphosphonates were not given systemically), or

3. the study was based on a non-osteoarthritic disease (e.g. osteochondrosis, infection, hemoarthrosis, tarsal sheath effusion, stringhalt), or

4. a non-equine model was used. Also excluded were nonEnglish language, non-systematic review articles, case reports, conference proceedings or duplicates

Inclusion: Either IA corticosteroids or systemic bisphosphonates were studied in horses with distal tarsal joint lameness due to OA 


\begin{tabular}{|c|c|c|c|c|}
\hline \multicolumn{5}{|c|}{ Search Outcome } \\
\hline Database & $\begin{array}{c}\text { Number of } \\
\text { results }\end{array}$ & $\begin{array}{c}\text { Excluded - did } \\
\text { not answer PICO } \\
\text { question }\end{array}$ & $\begin{array}{l}\text { Excluded - conference } \\
\text { proceedings, case } \\
\text { report or non- } \\
\text { systematic review } \\
\text { articles }\end{array}$ & Total relevant papers \\
\hline CAB Abstracts & 81 & 55 & 23 & 3 \\
\hline PubMed & 36 & 32 & 1 & 3 \\
\hline \multicolumn{4}{|c|}{ Total relevant papers when duplicates removed } & 3 \\
\hline
\end{tabular}

\section{CONFLICT OF INTEREST}

The author declares no conflicts of interest.

The author would like to thank Dr. Suzanne Fricke for introducing Evidence Based Veterinary Medicine into the curriculum at Washington State University College of Veterinary medicine and encouraging students to utilise this methodology.

\section{REFERENCES}

1. Dyson, S. \& Romero, J. (1993). An investigation of injection techniques for local analgesia of the equine distal tarsus and proximal metatarsus. Equine Veterinary Journal. 25(1), 30-35. DOI:

http://dx.doi.org/1111/i.2042-3306.1993.tb02897.x

2. Dyson, S. (1994). Proximal suspensory desmitis in the hindlimb: 42 cases. British Veterinary Journal. 150(3), 279-291. DOI: http://dx.doi.org/1016/S0007-1935(05)80008-9

3. De Grauw, J., Visser-Meijer, M., Lashley, F., Meeus, P. and van Weeren, P. (2016). Intra-articular treatment with triamcinolone compared with triamcinolone with hyaluronate: A randomized openlabel multicenter clinical trial in 80 lame horses. Equine Veterinary Journal. 48(2016), 152-158. DOI: http://dx.doi.org/10.1111/evj.12383

4. Gough, M., Thibaud, D. and Smith, R. (2010). Tiludronate infusion in the treatment of bone spavin: a double blind placebo-controlled trial. Equine Veterinary Journal. 42(5), 381-387. DOI:

http://dx.doi.org/10.1111/j.2042-3306.2010.00120.x

5. Hoaglund, E., Selberg, K., Seabaugh, K., Hess, A. and Bass, L. (2019). Comparing the clinical success rate of the dorsolateral approach to the medial approach for injection of the centrodistal joint in the horse. Equine Veterinary Journal. Electronic version March 10, 2019. DOI: http://dx.doi.org/10.1111/evj.13095

6. Labens, R., Mellor, D. \& Voûte, L. (2007). Retrospective study of the effect of intra-articular treatment of osteoarthritis of the distal tarsal joints in 51 horses. Veterinary Record. 161(18), 611-616. DOI: http://dx.doi.org/1136/vr.161.18.611 
7. Lamas, L., Edmonds, J., Hodge, W., Zamora-Vera, L., Burford, J., Coomer, R. \& Munroe, G. (2012). Use of ethanol in the treatment of distal tarsal joint osteoarthritis: 24 cases. Equine Veterinary Journal. 44(4), 399-403. DOI: http://dx.doi.org/10.1111/j.2042-3306.2011.00512.x

8. Seabaugh, K., Selberg, K., Mueller, P., Eggleston, R., Peroni, J., Claunch, K., Markwell, J. \& Baxter, G. (2017). Clinical study evaluating the accuracy of injecting the distal tarsal joints in the horse. Equine Veterinary Journal. 49(5), 668-672. DOI: http://dx.doi.org/10.1111/evj.12667

9. Watts, A., Dabareiner, R., Marsh, C., Carter, G. \& Cummings, K. (2016). A randomized, controlled trial of the effects of resveratrol administration in performance horses with lameness localized to the distal tarsal joints. Journal of the American Veterinary Medical Association. 249(6) 650-659. DOI: http://dx.doi.org/10.2460/javma.249.6.650

\section{Acknowledgement}

RCVS Knowledge was supported in producing this Knowledge Summary by an educational grant from Petplan Charitable Trust. 


\section{EVIIDEFeE

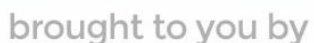 \\ RCVS KNOWLEDGE}

\section{Intellectual Property Rights}

Authors of Knowledge Summaries submitted to RCVS Knowledge for publication will retain copyright in their work, and will be required to grant RCVS Knowledge a non-exclusive license of the rights of copyright in the materials including but not limited to the right to publish, re-

publish, transmit, sell, distribute and otherwise use the materials in all languages and all media throughout the world, and to license or permit others to do so.

\section{Disclaimer}

Knowledge Summaries are a peer-reviewed article type which aims to answer a clinical question based on the best available current evidence. It does not override the responsibility

of the practitioner. Informed decisions should be made by considering such factors as individual clinical expertise and judgement along with patient's circumstances and owners' values. Knowledge Summaries are a resource to help inform and any opinions expressed within the Knowledge Summaries are the author's own and do not necessarily reflect the view of the RCVS Knowledge. Authors are responsible for the accuracy of the content. While the

Editor and Publisher believe that all content herein are in accord with current recommendations and practice at the time of publication, they accept no legal responsibility

for any errors or omissions, and make no warranty, express or implied, with respect to material contained within.

For further information please refer to our Terms of Use.

RCVS Knowledge is the independent charity associated with the Royal College of Veterinary Surgeons (RCVS). Our ambition is to become a global intermediary for evidence based veterinary knowledge by providing access to information

that is of immediate value to practicing veterinary professionals and directly contributes to evidence based clinical decision-making.

https://www.veterinaryevidence.org/

RCVS Knowledge is a registered Charity No. 230886.

Registered as a Company limited by guarantee in England and Wales No. 598443.

Registered Office: Belgravia House, 62-64 Horseferry Road, London SW1P 2AF

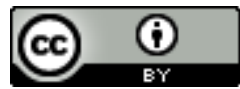

This work is licensed under a Creative Commons Attribution 4.0 International License. 